\title{
ENHANCEMENT OF SOLUBILITY AND DISSOLUTION OF NIMESULIDE USING SOLUBILIZATION, SOLID DISPERSION AND COMPLEXATION TECHNIQUES
}

\author{
S. Ismail, M. El-Mahdy and S. S. Al-Kubati
}

Department of Pharmaceutics, Faculty of Pharmacy, Assiut University, Assiut, Egypt

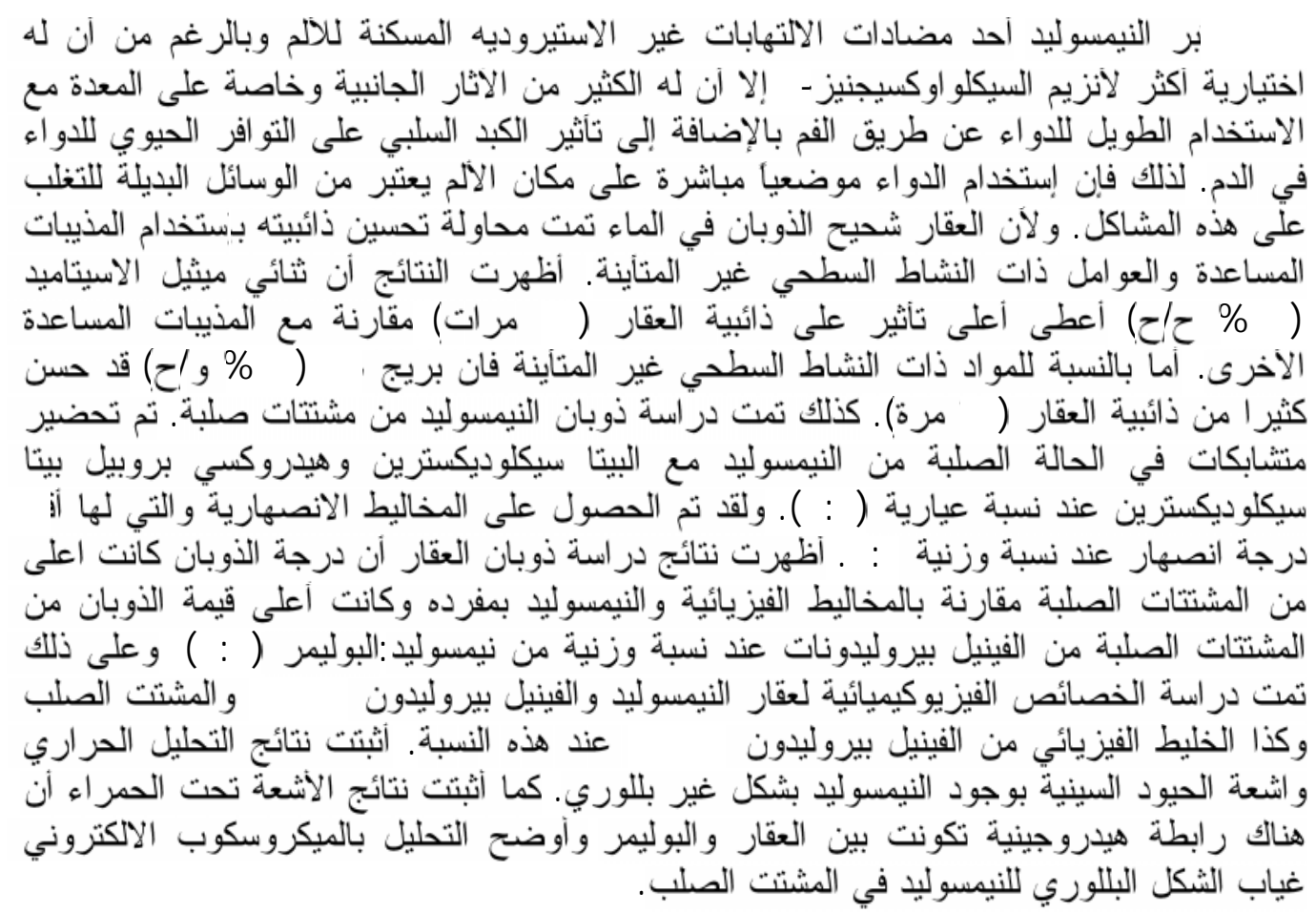

Nimesulide is a preferential COX-2 inhibitor. It has high anti-inflammatory, antipyretic and analgesic activities. It has poor aqueous solubility $(0.01 \mathrm{mg} / \mathrm{ml})$. Solubility of nimesulide was studied using different cosolvent mixtures and various classes of nonionic surfactants. Dimethylacetamide (DMA); at $10 \% \mathrm{v} / \mathrm{v}$ exhibited the highest solubilizing effect (10-fold) towards nimesulide as compared with other cosolvents. Among the tested nonionic surfactants at $10 \% \mathrm{w} / \mathrm{v}$, brij 58 which exhibited the highest solubilization effect (39-fold). The dissolution of nimesulide from solid dispersions was also studied. Solid inclusion complexes of nimesulide with $\beta$-cyclodextrin $(\beta-\mathrm{CD})$ and hydroxypropyl $\beta$-cyclodextrin (HP $\beta-C D)$ were prepared at a molar ratio of 1:1. Eutectic mixtures were obtained at weight ratio of 1:9 binary systems as confirmed by DSC studies. The dissolution studies indicated that the highest relative amounts dissolved were obtained from solid dispersions as compared with physical mixtures or pure nimesulide. Also higher relative amounts dissolved were obtained with polyvinylpyrrolidones (PVPs) at weight ratio of nimesulide/PVP 40000 1:7. Physicochemical characterization of pure drug, PVP 40000, nimesulide/PVP 40000 solid dispersion and the physical mixture at this ratio were conducted by DSC, FTIR, X-RPD and SEM. The DSC thermograms and X-RPD patterns demonstrated that nimesulide existed in an amorphous form and there is an intermolecular hydrogen bond between the drug and the carrier as shown from FTIR analysis. SEM images confirmed the absence of the crystalline structure of nimesulide in the solid dispersion.

\section{INTRODUCTION}

The dissolution enhancement of poorly water-soluble drugs can be achieved by several techniques, such as micronization ${ }^{1 \& 2}$, recrystallization $^{3}$, inclusion complexation ${ }^{4}$, cogriding $^{5}$ and solid dispersion ${ }^{6}$. Cosolvents as ethanol, propylene glycol, polyethylene glycols 
and glycerin are routinely used as a means for solubilization of drugs in aqueous vehicles ${ }^{7}$. Dimethylsufoxide (DMSO) and dimethylacetamide (DMA) have been widely used because of their large solubilizing capacity for poorly water-soluble drugs ${ }^{8}$. They are organic compounds that are substantially miscible with water and having small hydrocarbon regions. This leads to a reduction of the ability of water to squeeze out nonpolar hydrophobic compound and consequently enhance its aqueous solubility'.

Micellization is the technique by which the water insoluble or slightly water soluble drugs are solubilized by the aid of surfactants above their respective critical micelle concentration $^{10}$. In virtue of their relatively low toxicity and high solubilizing power; nonionic surfactants have been awarded major attention for promoting solubilization ${ }^{11}$.

Solid dispersion in which the compound is dispersed as a molecular form combines the benefits of increasing the solubility and maximizing the surface area of the compound that comes in contact with the dissolution medium into which the carrier freely dissolves $^{12}$. It is considered a useful pharmaceutical technique for increasing the dissolution, absorption and therapeutic efficacy of drugs when incorporated in dosage forms ${ }^{13}$. The most commonly used water soluble carriers in solid dispersion technique are solid polyethylene glycols, polyvinyl pyrrolidones ${ }^{14}$ and poloxamers ${ }^{15}$.

Cyclodextrins (CDs) have attracted growing interest in the pharmaceutical industry as complexing agents, because of their low toxicity and ability to produce stable complexes. Cyclodextrins play an important role in formulation of poorly water-soluble drugs by acting as hydrophilic carriers. Reduction of drug crystallinity on complexation with CDs also contributes to increase apparent drug solubility and dissolution rate ${ }^{16}$.

Nimesulide is a prefrerential selective COX-2 inhibitor; it inhibits the prostaglandin synthesis from arachidonic acid by inhibiting the COX pathway. It is 5-16 fold selective for COX-2 than COX $-1{ }^{17}$. The drug is poorly water soluble and its aqueous solubility is 0.01 $\mathrm{mg} / \mathrm{ml}$. It is a weakly acidic NSAID having a pKa of $6.4-6.8^{18}$. It has some gastrointestinal adverse effects especially on long term administration. Furthermore, it is extensively metabolized in the liver when administered orally. Consequently, topical application of nimesulide is desirable to alleviate pain without systemic adverse effects. Moreover, nimesulide has a poor aqueous solubility belonging to class II drugs of low solubility and high permeability. Thus, the aim of this study is to enhance the solubility and the dissolution of nimesulide using cosolvency, micellar solubilization, solid dispersion and complex formation techniques so as to formulate it in suitable semisolid dosage forms.

\section{EXPERIMENTAL}

\section{Materials}

Nimesulide was kindly supplied by Alkan Pharma Co., Egypt; Dimethylsulphoxide (DMSO), BDH Chemicals Ltd. Poole, England; Isopropanol, ethanol, methanol, dimethyl formamide (DMF), propylene glycol (PG) and glycerol, El-Nasr Pharmaceutical Chemicals Co. Egypt; polyoxyethylene (20) sorbitan monolaurate (Tween 20), polyoxyetylene (20) sorbitan monopalmitate (Tween 40) and Polyoxyetylene (20) sorbitan monooleate (Tween 80), Polyoxyethylene (50) stearate (Myrj 53), polyoxyethylene (40) stearate (Myrj 52), Polyvinyl pyrrolidone 40000 (PVP 40000), polyvinyl pyrrolidone K25 (PVP K25), pluronic F-68 and pluronic F-127, Sigma Chemical Co., USA; polyoxyethylene (23) lauryl ether (Brij 35), polyoxyethylene (20) cetyl ether (Brij 58), Ethylene Glycol (EG), polyethylene glycol 200 (PEG 200), polyethylene glycol 300 (PEG 300) Polyethylene glycol 4000 (PEG 4000), polyethylene glycol 6000 (PEG 6000), and N,N-dimethylacetamide (DMA), MerkSchuchardt, Germany; Formamide, Analar ${ }^{\circledR}$ Searle Co. Hopkin and Williams, England; Propanol, Aldrich Chemical Co. Ltd., England; $\beta$-cyclodextrin ( $\beta$-CD), Acros Organics, USA and 2-hydroxypropyl $\beta$-cyclodextrin (HP- $\beta$ CD), Fluka, Japan. All other chemicals used were of analytical grade.

\section{Methods}

\section{Assessment of nimesulide solubility}

Solubility of nimesulide in phosphate buffer $\mathrm{pH} \quad 6.8$ in presence of different 
concentrations $2-10 \%(\mathrm{v} / \mathrm{v}$ or $\mathrm{w} / \mathrm{v})$ of some selected cosolvents was investigated. The selected cosolvents were: formamide, DMF, DMA, DMSO, ethanol, propanol, isopropanol, glycerol, EG, PG, PEG 200, PEG 300, PEG 400 and PEG 600. In addition, the solubility in presence of different concentrations $2-10 \%$ $(\mathrm{w} / \mathrm{v})$ of different nonionic surfactants (tween 20 , tween 40 , tween 80 , myrj 52 , myrj 53 , brij 35 and brij 58) was also studied. An excess amount of nimesulide was added to $50-\mathrm{ml}$ stoppered glass bottles containing $10 \mathrm{ml}$ cosolvent solutions or surfactant solutions. The bottles were shaken in a mechanical shaking water bath previously equilibrated at $32^{\circ} \mathrm{C}$. Aliquots were withdrawn after three hours (equilibrium time), filtered using a $0.45 \mu \mathrm{m}$ membrane disc filter and assayed spectrophotometrically at $\lambda_{\max } 392 \mathrm{~nm}\left(\lambda_{\max }\right.$ was determined practically) after appropriate dilution employing the same concentration of the cosolvent or surfactant as a blank. The results are the mean values of three determinations.

\section{Assessment of dissolution of nimesulide from solid dispersions and inclusion complexes \\ Preparation of physical mixtures}

Nimesulide and the selected carriers were sieved through a sieve no. of $60(250 \mu \mathrm{m}$ pore size), then the physical mixtures containing PEG 4000, PEG 6000, pluronic F-68 and pluronic F-127 at a weight ratio of nimesulide/carrier of 1:9 were prepared. Physical mixtures of nimesulide and carriers PVP K25 as well as PVP 40000 were prepared at a weight ratio of 1:7. $\beta-C D$ and HP $\beta-C D$ physical mixtures were prepared at equimolar ratio of $1: 1$ by simple mixing using spatula and paper.

\section{Preparation of nimesulide solid dispersions 1- Fusion method}

Solid dispersions of nimesulide with PEG 4000, PEG 6000, pluronic F-68 and pluronic F127 in different weight ratios of nimesulide/carrier were prepared by fusion method. Nimesulide was fused until melted then the carrier was added and the mixture was stirred until completely mixed and the stirring was continued at room temperature until cooled, then stored in a desiccator containing anhydrous calcium chloride for $24 \mathrm{hrs}$ (this time was found to be sufficient for complete drying of the powder). The obtained solid mass was ground in a mortar and passed through sieve no. 60 ( $250 \mu \mathrm{m}$ pore size $)$.

\section{2- Coprecipitation method}

Since fusion method can not be applied due to the high glass transition temperature $\left(\mathrm{T}_{\mathrm{g}}\right)$ of PVP K25 and PVP 40000, coprecipitation method was used to prepare solid dispersions of nimesulide with these carriers. Different drug/carrier ratios: 1:1, 1:3, 1:5 and 1:7 were used to prepare the solid dispersions. The calculated amounts of nimesulide and the carrier were dissolved in a minimum amount of methanol. The solvent was allowed to evaporate at room temperature and the residue was dried at $40^{\circ} \mathrm{C}$ in a hot air oven until constant weight of the residue is obtained (24 hrs). The dried mass was placed in a desiccator containing anhydrous calcium chloride for further $24 \mathrm{hrs}$. The obtained solid mass was ground and passed through sieve no. 60 (250 $\mu \mathrm{m}$ pore size).

\section{Preparation of solid inclusion complexes}

The complexation of nimesulide with $\beta$ $\mathrm{CD}$ and HP $\beta$-CD both in solution and solid state to improve the dissolution behavior of nimesulide was previously studied ${ }^{19 \& 20}$. The solubility phase diagrams of nimesulide/CDs solutions from these studies revealed 1:1 molar ratio complexation of nimesulide with these CDs. Accordingly nimesulide/ $\beta-C D$ and nimesulide/HP $\beta$-CD coprecipitated solid complexes and physical mixtures were prepared in 1:1 molar ratio. An equimolar ratio of $1: 1$ of nimesulide and $\beta-C D$ was prepared by adding the aqueous $\beta-\mathrm{CD}$ solution to the methanolic solution of nimesulide. The obtained mixture was stirred for one hour and allowed to evaporate at $40^{\circ} \mathrm{C}$ in a hot air oven until dry. The dried mass was placed in a desiccator containing anhydrous calcium chloride for further $24 \mathrm{hrs}$ then ground and passed through sieve no. $60(250 \mu \mathrm{m}$ pore size).

The inclusion complex of nimesulide with HP $\beta-C D$ was prepared by dissolving an equimolar ratio of $1: 1$ of nimesulide and HP $\beta$ $\mathrm{CD}$ in methanol and then the solvent was allowed to evaporate at room temperature and 
the residue was dried at $40^{\circ} \mathrm{C}$ in a hot air oven for $24 \mathrm{hrs}$. The dried mass was placed in a desiccator containing anhydrous calcium chloride for further $24 \mathrm{hrs}$. The obtained solid mass was ground and passed through sieve no. $60(250 \mu \mathrm{m}$ pore size $)$.

\section{Construction of phase diagrams}

The phase diagrams of nimesulide with the tested carriers were constructed. This was achieved by using a melting point apparatus (Stuart scientific melting point SMP1, UK). The samples were placed in glass capillary tubes and heated at a rate $5^{\circ} \mathrm{C} /$ minute. The melting points were recorded by visual observation of complete melting of the samples using a high power magnifying glass lens fixed on the mount of the samples and a heating stage. The results are the mean values of two determinations.

\section{Dissolution studies}

The dissolution of nimesulide alone, from its solid dispersions and the corresponding physical mixtures were studied using USP XXIV type II dissolution apparatus, paddle type (Electrolab, TDT-06N, India). Accurately weighed amounts equivalent to $20 \mathrm{mg}$ of nimesulide were dispersed over the dissolution medium, $900 \mathrm{ml}$ phosphate buffer at $\mathrm{pH} 6.8$, and at $32 \pm 0.2^{\circ} \mathrm{C}$, stirred at $50 \mathrm{rpm}$. At appropriate time intervals, $5 \mathrm{ml}$ samples were withdrawn over a period of $3 \mathrm{hrs}$ and replaced by an equal volume of fresh dissolution medium at the same temperature. The samples were filtered using a $0.45 \mu \mathrm{m}$ membrane disc filter and assayed spectrophotometrically at $\lambda_{\max } 392 \mathrm{~nm}$. The results are the mean values of three determinations.

\section{Characterization of nimesulide solid dispersion with PVP 40000 \\ 1- Differential scanning calorimetry (DSC)}

Differential Scanning Calorimetric (DSC) analysis of the pure drug, carriers, solid dispersions and physical mixtures of nimesulide with PEG 4000, PEG 6000, pluronic F-68 and pluronic F-127 at a weight ratio of 1:9 was performed using ShimadzuThermal analyzer DSC-T50, Japan, calibrated with indium. 4-5 mg samples heated under nitrogen atmosphere on a sealed aluminum pans at a rate of $10^{\circ} \mathrm{C} /$ minute over the temperature range of $30-300^{\circ} \mathrm{C}$. Solid dispersion and physical mixture of nimesulide with PVP 40000 at a weight ratio of 1:7 were also measured.

\section{2- X-Ray powder diffraction analysis (X- RPD)}

X-ray powder diffraction patterns of pure nimesulide, PVP 40000, solid dispersion and physical mixture of nimesulide with PVP 40000 at a weight ratio of 1:7 were performed using Philips PW1710 diffractometer, USA. The samples were irradiated with Cuk $\alpha$ radiation with a wavelength of $1.5418 \mathrm{~A}^{\circ}$ at 40 $\mathrm{Kv}$ and $40 \mathrm{~mA}$, then analyzed between $2 \theta$ angles of $4-60^{\circ}$ at a scan rate of $0.06^{\circ} \% \mathrm{~min}$.

\section{3- Infrared spectrophotometry (IR)}

The IR spectra of pure drug, PVP 40000, solid dispersion and physical mixture of nimesulide with PVP 40000 at a weight ratio of 1:7 were recorded using Shimadzu IR-470 spectrophotometer, Japan, at a range of 4000$400 \mathrm{~cm}^{-1}$ using $\mathrm{KBr}$ disk method. The samples were mixed with $\mathrm{KBr}$ and compressed into discs using IR compression machine.

\section{4- Scanning electron microscopy (SEM)}

Samples of pure drug, PVP 40000, solid dispersion and the corresponding physical mixture at weight ratio of 1:7 were mounted onto the stub using double-sided adhesive tape and then coated with gold palladium alloy using fine coat ion sputter. The samples were subsequently analyzed under the electron microscope (JSM 5400LV, Jeol, Japan) to obtain digital images of the samples.

\section{RESULTS AND DISCUSSION}

\section{Assessment of nimesulide solubility using cosolvency technique}

The equilibrium solubility of nimesulide in phosphate buffer at $\mathrm{pH} 6.8$ and $32^{\circ} \mathrm{C}$ was determined. It was found that nimesulide achieved an equilibrium solubility of 8.827 $\mu \mathrm{g} / \mathrm{ml}$ after $3 \mathrm{hrs}$.

The effect of different concentrations of various cosolvents: DMA, DMF, DMSO, formamide, isopropanol, propanol, ethanol, PG, EG, glycerol, PEG 200, PEG 300, PEG 400 and PEG 600 at concentrations ranging from 2$10 \%$ on the aqueous solubility of nimesulide 
are presented in Table 1. All cosolvents displayed an increase in the solubility and there was a direct relationship between the solubility and the concentration of the cosolvents used. The order of increasing solubility using cosolvents at $10 \%$ concentration is shown in Table 1; DMA exhibited the highest value of $85.306 \mu \mathrm{g} / \mathrm{ml}$ (9.7-fold) whereas glycerol showed the lowest value of $14.877 \mu \mathrm{g} / \mathrm{ml}$ (1.7fold) among the investigated cosolvents. This can be explained by the fact that glycerol is quite a polar solvent. Since the less polar cosolvent, is the more effective one in disrupting hydrogen bonding between water molecules. This in turn, reduces the ability of a newly formed solvent (aqueous-cosolvent mixture) to squeeze out nonpolar drugs. As a result, nonpolar drugs such as nimesulide can be solubilized more efficiently by DMA, the least polar cosolvent. These results are in agreement with those obtained by Kawakami et $a l^{8}$ on phenytoin and Zhao and Yalkowsky ${ }^{21}$ on fluasterone, in which the increase in solubility of drugs depends on concentration and the polarity of cosolvents used.

Table 1: Solubility of nimesulide in phosphate buffer containing $10 \%$ cosolvents.

\begin{tabular}{||l|c|c||}
\hline \multicolumn{1}{|c|}{ Cosolvent } & $\begin{array}{c}\text { Solubility } \\
(\mu \mathrm{g} / \mathrm{ml})\end{array}$ & $\begin{array}{c}\text { "Solubility } \\
\text { efficiency }\end{array}$ \\
\hline DMA* & 85.31 & 9.7 \\
\hline DMF* $^{*}$ & 71.17 & 8.1 \\
\hline DMSO* $^{*}$ & 48.09 & 5.4 \\
\hline Formamide* & 45.49 & 5.2 \\
\hline PEG 600** & 37.41 & 4.2 \\
\hline PEG 400** & 34.81 & 3.9 \\
\hline PEG 300** & 32.07 & 3.6 \\
\hline Isopropanol* & 31.98 & 3.6 \\
\hline Propanol* & 30.25 & 3.5 \\
\hline Ethanol* & 29.19 & 3.3 \\
\hline PEG 200** & 28.78 & 3.3 \\
\hline PG** & 21.05 & 2.4 \\
\hline EG** & 15.74 & 1.8 \\
\hline Glycerol** & 14.88 & 1.7 \\
\hline
\end{tabular}

$*(\% \mathrm{v} / \mathrm{v}) . \quad * *:(\% \mathrm{w} / \mathrm{v})$.

N.B.: The solubility of nimesulide in phosphate buffer $\mathrm{pH} 6.8$ and $32^{\circ} \mathrm{C}$ is $8.827 \mu \mathrm{g} / \mathrm{ml}$.

${ }^{\text {\#}}$ Solubility efficiency=

The solubility of nimesulide in presence of cosolvent Solubility of nimesulide in phosphate buffer
The solubility of nimesulide was enhanced markedly by increasing cosolvents concentrateions. At $10 \%$ of DMA, DMF, DMSO and formamide, the solubility was enhanced to about 9.7, 8.1, 5.4 and 5.2 fold, respectively. This is in accordance with the cosolvent polarity. Alkylation of formamide increases the solubilizing effect. In alcoholic cosolvents, the solubility of nimesulide was increased by increasing the concentration of alcohols. Isopropanol; the least polar cosolvent exhibited $31.98 \mu \mathrm{g} / \mathrm{ml}$ (3.6-fold) whereas ethanol; the most polar cosolvent among investigated alcoholic cosolvents exhibited $29.19 \mu \mathrm{g} / \mathrm{ml}$ (3.3-fold). Similar results were obtained when fluasterone was solubilized in methanol, ethanol and propanol, in which methanol exhibited the lowest solubilizing effect and propanol exhibited the highest solubilizing effect on fluasteron ${ }^{22}$. PG, EG and glycerol exhibited solubility effect of $21.049 \mu \mathrm{g} / \mathrm{ml}$, $15.74 \mu \mathrm{g} / \mathrm{ml}$ and $14.88 \mu \mathrm{g} / \mathrm{ml}$, respectively. On comparing the effect of PEGs on the aqueous solubility of nimesulide, it could be ranked in the following descending order: PEG $600>$ PEG $400>$ PEG $300>$ PEG 200. It is evidenced that by increasing the chain length of PEGs suggesting an interaction between nimesulide and the tested PEGs ${ }^{23}$.

\section{Assessment of nimesulide solubility using micellar solubilization technique}

The solubilizing effect of different nonionic surfactants; polysorbates (tweens), polyoxyethylene stearates (myrjs) and polyoxethylene alkyl ethers (brijs) was investigated at $2-10 \%(\% \mathrm{w} / \mathrm{v})$ concentrations. A marked increase in the drug solubility was obtained with all tested surfactants and was increased with an increase in the surfactants concentrations. At $10 \%$ concentration, brij 58 sowed the highest solubilizing value of 343.15 $\mu \mathrm{g} / \mathrm{ml}$ (39-fold) while tween 20 enhanced nimesulide solubility up to $171.79 \mu \mathrm{g} / \mathrm{ml}(19.5$ fold) (Table 2). The increase in nimesulide solubility by the investigated tweens could be ranked in a descending order as tween $80>$ tween $40>$ tween 20. Tweens have the same hydrophilic portion in their molecules but differ in the length of the lipophilic portion. Nonpolar compounds are generally solubilized in the hydrocarbon interior of the micelle ${ }^{24}$. It is clearly evidenced that the solubilization 
effects of these micelle forming agents is increased as the hydrophobic chain length of the surfactant is increased. This is due to an increase in the volume of the hydrocarbon in the micelle interior. In addition, the increase in the alkyl chain length increases the size of the surfactant micelle which accommodates more quantity of nonpolar solute and hence increases its solubilization effect. Similar results were obtained with carbamazepin ${ }^{24}$ and nalidixic $\operatorname{acid}^{25}$.

Table 2: Solubility of nimesulide in phosphate buffer containing $10 \% \quad(\mathrm{w} / \mathrm{v})$ nonionic surfactants.

\begin{tabular}{||l|c|c||}
\hline Surfactant & $\begin{array}{c}\text { Solubility } \\
(\mu \mathrm{g} / \mathrm{ml})\end{array}$ & $\begin{array}{c}{ }^{\text {"}} \text { Solubility } \\
\text { Efficiency }\end{array}$ \\
\hline Brij 58 & 343.149 & 38.9 \\
\hline Myrj 52 & 291.944 & 33.1 \\
\hline Brij 35 & 267.930 & 30.4 \\
\hline Tween 80 & 212.20 & 24.0 \\
\hline Myrj 53 & 197.337 & 22.4 \\
\hline Tween 40 & 190.69 & 21.6 \\
\hline Tween 20 & 171.79 & 19.5 \\
\hline
\end{tabular}

N.B.: The solubility of nimesulide in phosphate buffer $\mathrm{pH} 6.8$ and $32^{\circ} \mathrm{C}$ is $8.827 \mu \mathrm{g} / \mathrm{ml}$.

\begin{tabular}{l}
${ }^{\#}$ Solubility efficiency $=$ \\
The solubility of nimesulide in presence of surfactant \\
\hline Solubility of nimesulide in phosphate buffer
\end{tabular}

The effect of myrj 52 and myrj 53 on the solubility of nimesulide is shown in Table 2. It is clearly observed that the effect of myrj 52 $(291.94 \mu \mathrm{g} / \mathrm{ml})$; (33-fold) was greater than myrj $53(197.34 \mu \mathrm{g} / \mathrm{ml}) ;$ (22-fold). It could be noticed that the ability of solubilization decreases with increasing the length of polyoxyethylene chain. This may be explained by the fact that the micellar size of surfactant decreased as poloxyethylene chain length increased ${ }^{24 \& 26}$.

The effect of two different brijs on the aqueous solubility of nimesulide is shown in Table 2. Higher increase value $343.15 \mu \mathrm{g} / \mathrm{ml}$ (39 fold) in drug solubility was obtained by brij 58 while brij 35 exhibited a lower solubilizing effect $267.93 \mu \mathrm{g} / \mathrm{ml}$; (30 fold). This is due to the difference in the hydrocarbon chain length of each surfactant. Lengthening of the hydrocarbon chain causes an increase in the micellar size. The larger hydrocarbon chain provides a greater driving force for micellization than a short one $\mathrm{e}^{24 \& 27}$. Obviously, the effect of these classes of nonionic surfactants on the solubility of nimesulide can be arranged in the following descending order: brij $58>$ myrj $52>$ brij $35>$ tween $80>$ myrj $53>$ tween $40>$ tween 20 (Table 2).

\section{Construction of phase diagram}

As shown in Figure 1, the presence of the carriers causes a depression of the melting point of nimesulide in all binary mixtures and the melting points of both nimesulide and the carriers were depressed at a ratio of 1:9. The eutectic points were found to be $55,58,50$ and $52^{\circ} \mathrm{C}$ for nimesulide/PEG 4000, nimesulide/PEG 6000, nimesulide/pluronic F-68 and pluronic F-127, respectively.

The DSC thermograms of pure nimesulide, PEG 4000, PEG 6000, pluronic $\mathrm{F}$ 68 and Pluronic F-127, solid dispersions and physical mixtures at weight ratio of 1:9 are shown in Figures 2 and 3, respectively. Nimesulide trace showed a single endothermic peak with a melting point of $151.4^{\circ} \mathrm{C}$. Whereas the carriers; PEG 4000, PEG 6000, pluronic F68 and pluronic F-127 traces have single endothermic peaks at $58.7^{\circ} \mathrm{C}, 63.4^{\circ} \mathrm{C}, 53.4^{\circ} \mathrm{C}$ and $56.2^{\circ} \mathrm{C}$, respectively which are corresponding to the melting points of these carriers. These revealed the existence of nimesulide and these carriers in a crystalline state. DSC thermograms of solid dispersions of nimesulide with these carriers showed single endothermic peaks shifted to lower melting points than nimesulide and the carriers, confirm the formation of eutectic systems. On the other hand physical mixtures showed one endothermic peaks, corresponding to the melting points of the carriers and the disappearance of nimesulide endothermic peak may be due to its solubility in the melted carriers during heating ${ }^{15,28 \& 29}$. Bikiaris et al. ${ }^{29}$ concluded that the absence of melting peak of felodepin and hesperetin in the case of solid dispersions was not because the drugs were amorphous, but due to the increase in drug solubility in the liquid PEG at elevated temperature. 


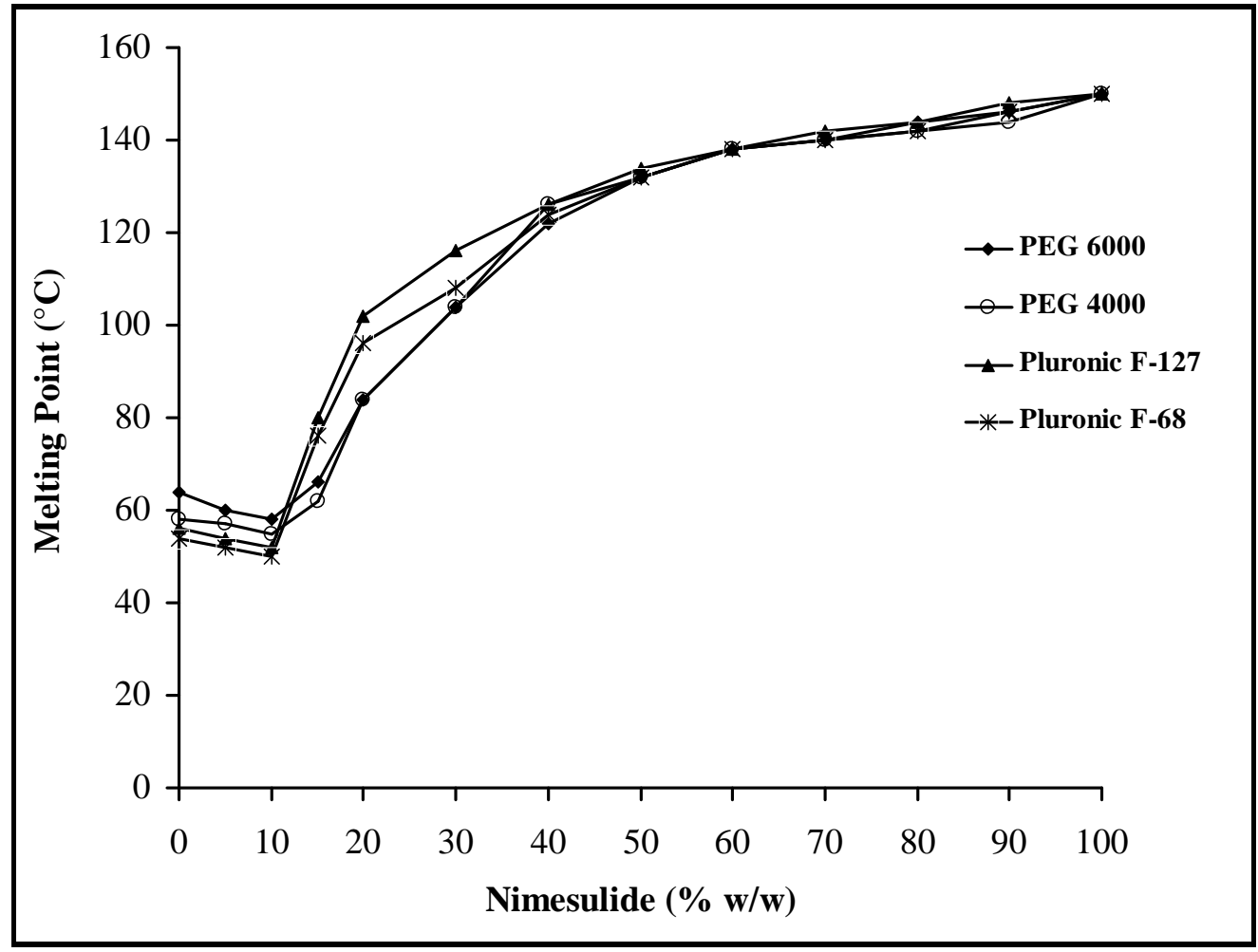

Fig. 1: Phase diagram of nimesulide/polyethylene glycol 6000, nimesulide/polyethylene glycol 4000, nimesulide/pluronic F-127 and nimesulide/pluronic F-68 solid dispersions.

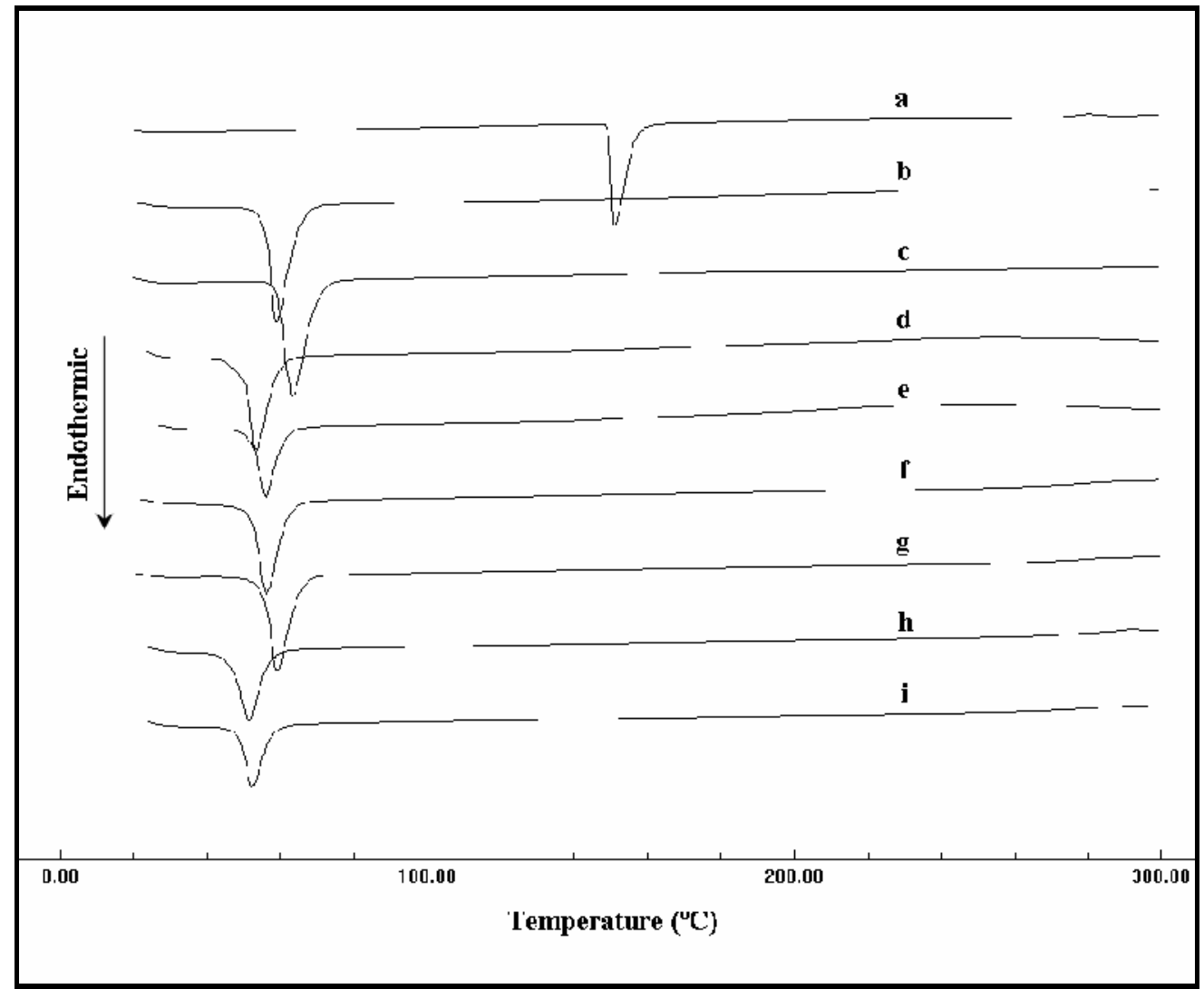

Fig. 2: DSC thermograms of (a): nimesulide, (b): PEG 4000, (c): PEG 6000, (d): pluronic F-68, (e): pluronic F-127, and solid dispersions at weight ratio of 1:9 of (f): nimesulide/PEG 4000, (g): nimesulide/PEG 6000, (h): nimesulide/Pluronic F-68 and (i): nimesulide/pluronic F-127. 


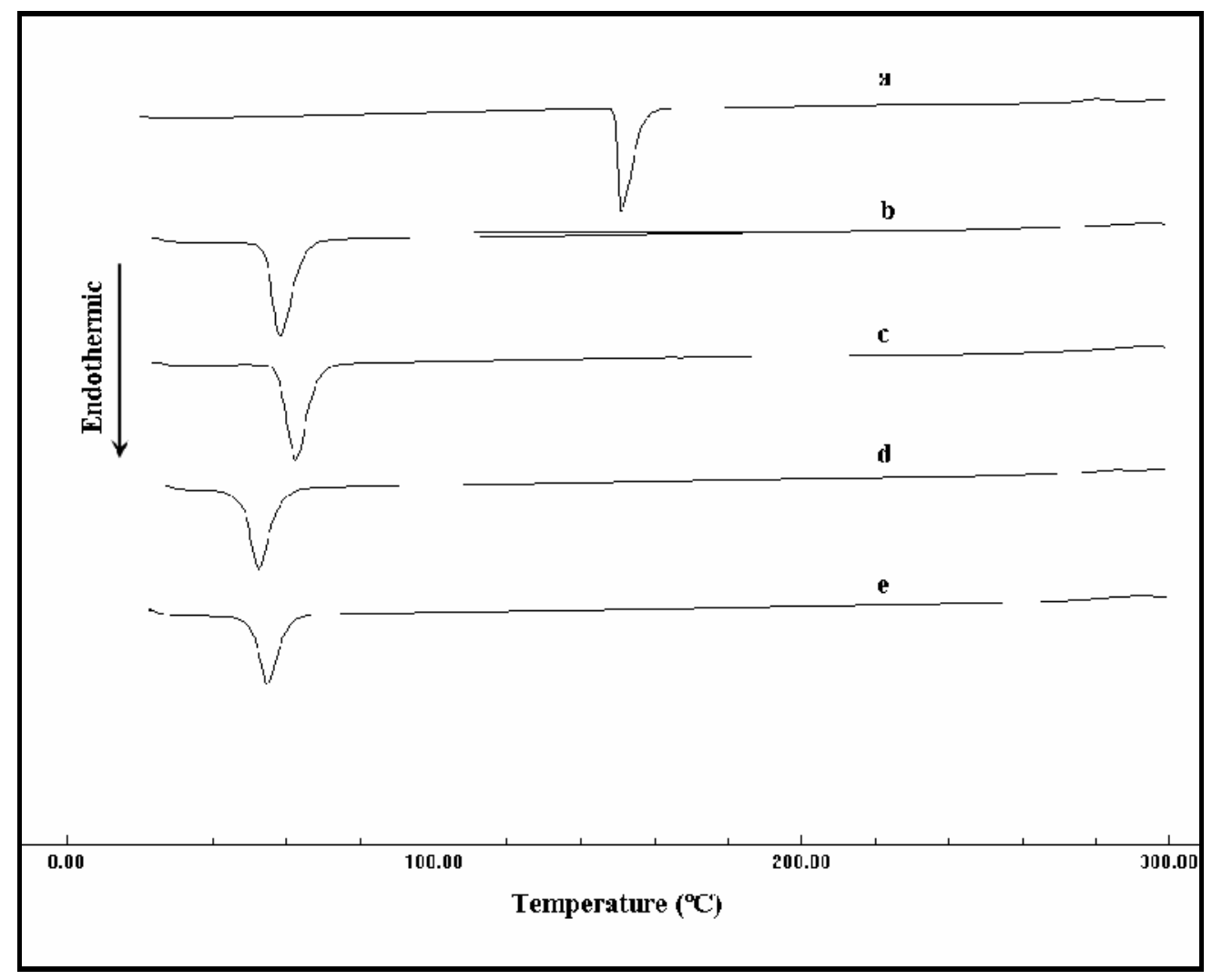

Fig. 3: DSC thermograms of (a): nimesulide, and physical mixtures at weight ratio of 1:9 of (b): nimesulide/PEG 4000, (c): nimesulide/PEG 6000, (d): nimesulide/pluronic F-68 and (e): nimesulide/pluronic F-127.

\section{Dissolution studies}

Figure 4 illustrates the dissolution of nimesulide from its solid dispersions and physical mixtures with PEG 4000 and PEG 6000. It is evident that the dissolution of pure nimesulide is very slow, about $1.99 \mathrm{mg}$ after 15 minutes. Dispersion of nimesulide in these hydrophilic carriers considerably enhanced the dissolution. Table 3 shows the relative amount dissolved (R.A.D) of nimesulide from the solid dispersion and inclusion complexes as well as the physical mixture after 15 minutes. It is clearly obvious that nimesulide/PEG 4000 and nimesulide/PEG 6000 solid dispersions exhibited faster dissolutions of about $6.40 \mathrm{mg}$ (3.2-fold) and $7.36 \mathrm{mg}$ (3.7-fold), respectively after 15 minutes as compared with the pure drug. The observed increase in the dissolution of nimesulide from its solid dispersions could be attributed to improved wettability, local solubilization and drug particles size reduction. Similar observation by Khan and Jiabi for ibuprofen solid dispersion with PEG 10000 was obtained $^{30}$. Dissolution from the physical mixture was faster than pure drug. Drug mixing brings the drug in close contact with the hydrophilic carrier resulting in increased wettability and dispersibility of nimesulide. During dissolution experiments, it was noticed that the physical mixtures immediately sink to the bottom of the dissolution vessels, whereas the pure drug floats for a long period of time on the surface of the dissolution medium, thereby, decreasing effective surface area of the particles exposed to the dissolution medium.

The results of dissolution tests of nimesulide from its solid dispersions and physical mixtures with pluronic F-68 and pluronic F-127 is shown in Figure 5. Nimesulide/pluronic F-68 and nimesulide/ pluronic F-127 solid dispersions exhibited faster dissolutions of about $8.22 \mathrm{mg}$ (4.1-fold) and $9.05 \mathrm{mg}$ (4.5-fold), respectively after 15 minutes compared with the pure drug (Table $3)$. The fact that the solid dispersions were miscible in the liquid state and immiscible in the solid state indicate that they might have been crystallized out simultaneously as microfine crystals from the molten mixtures resulting in an increase in nimesulide surface 
Table 3: Relative amounts of nimesulide dissolved after 15 minutes from solid dispersion, inclusion complexes and physical mixtures with different carriers.

\begin{tabular}{||c|c|c||}
\hline \multirow{2}{*}{ System } & Preparation & $\begin{array}{c}\text { R.A.D* after 15 } \\
\text { minutes }\end{array}$ \\
\hline \multirow{2}{*}{ PEG 4000 } & Physical mixture & 1.7 \\
\cline { 2 - 3 } & Solid dispersion & 3.2 \\
\hline \multirow{2}{*}{ PEG 6000 } & Physical mixture & 2.2 \\
\cline { 2 - 3 } & Solid dispersion & 3.7 \\
\hline \multirow{2}{*}{ Pluronic F-68 } & Physical mixture & 3.8 \\
\cline { 2 - 3 } & Solid dispersion & 4.1 \\
\hline \multirow{2}{*}{ Pluronic F-127 } & Physical mixture & 4.2 \\
\cline { 2 - 3 } & Solid dispersion & 4.5 \\
\hline \multirow{2}{*}{ PVP K 25 } & Physical mixture & 2.4 \\
\cline { 2 - 3 } & Solid dispersion & 5.6 \\
\hline \multirow{2}{*}{ PVP 40000 } & Physical mixture & 2.5 \\
\cline { 2 - 3 }$\beta-C D$ & Solid dispersion & 5.6 \\
\hline \multirow{2}{*}{ H-CD $\beta-C D$} & Physical mixture & 2.0 \\
\cline { 2 - 3 } & complex & 3.0 \\
\hline \multirow{2}{*}{ Physical mixture } & 2.8 \\
\cline { 2 - 3 } & complex & 3.0 \\
\hline
\end{tabular}

$*($ R.A.D $)=\frac{\text { Amount } \text { of the drug dissolved in presence of carrier }}{\text { Amount of the drug dissolved alone }}$

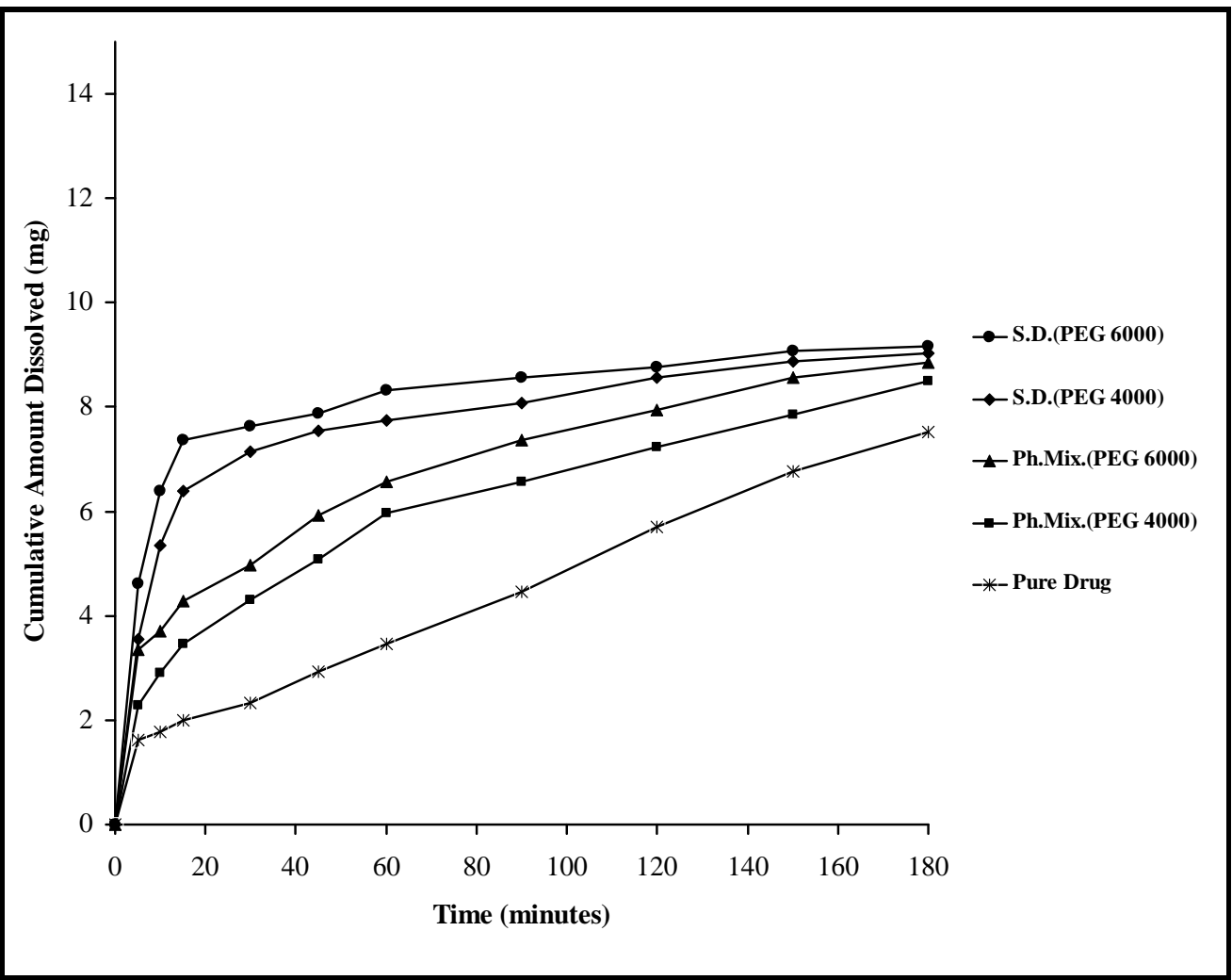

Fig. 4: Dissolution profiles of nimesulide from its physical mixtures (Ph. Mix.) and solid dispersions (S.D.) with PEG 4000 and PEG 6000. 


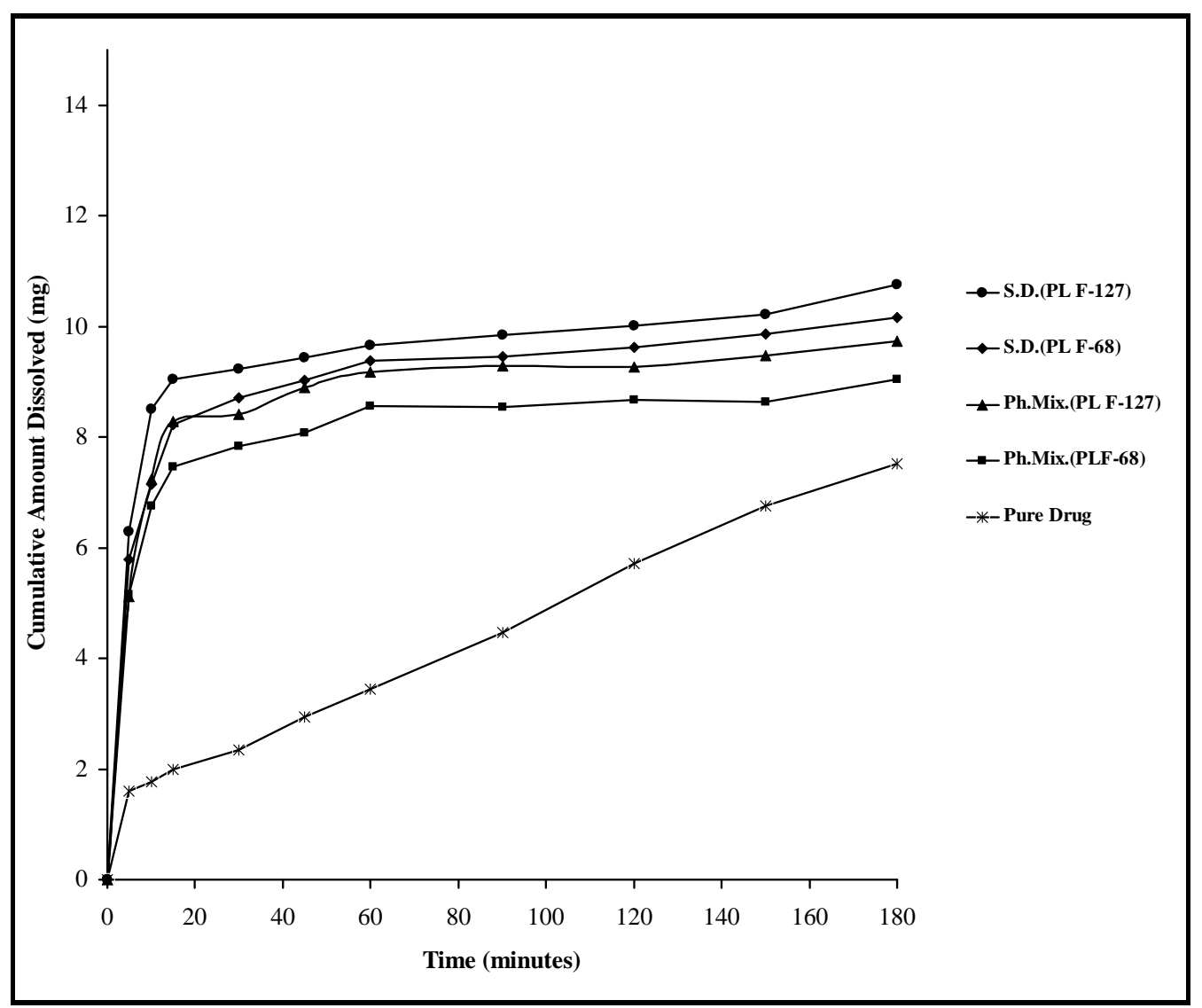

Fig. 5: Dissolution profiles of nimesulide from its physical mixtures (Ph. Mix.) and solid dispersions (S.D.) with pluronic F-68 (PL F68) and pluronic F-127 (PL F-127).

area. The enhancement of dissolution from solid dispersions may be attributed partly to the reduction in particles size of nimesulide crystals due to formation of eutectic mixtures with pluronics, along with eutectic mixtures, surface activity, wetting and solubilization effect of pluronics. Enhanced dissolution of nimesulide from physical mixtures could be correlated to the chemical structures of highly water soluble pluronics. Reportedly, the hydrophobic core can act as reservoir for the drug while the hydrophilic portion acts as interface between the aqueous medium and the drug. Consequently, enhancement in dissolution could be possibly of combined action of surface activity, solubilization and wettability effects of pluronics ${ }^{31-34}$.

The dissolution of nimesulide from its solid dispersions with PVP K25 and PVP 40000 at ratios of 1:1, 1:3, 1:5 and 1:7 and from physical mixtures at a weight ratio of $1: 7$ is shown in Figures 6 and 7. It can be noticed that the dissolution of the drug is increased as the amount of the tested carrier is increased in the solid dispersions. Previous studies indicated that the increase in dissolution can be achieved by increasing in the amount of PVP in the solid dispersions ${ }^{35}$. Solid dispersions and physical mixtures prepared in a weight ratio of 1:7 PVP K25 or PVP 40000 exhibited a faster dissolutions of about $11.13 \mathrm{mg}$ (5.6-fold) and $11.07 \mathrm{mg}$ (5.6-fold), respectively after 15 minutes as compared with the pure drug (Table 3 ). This may be attributed to the changes in the solid state during the formation of dispersion and the formation of high-energy amorphous phase as supported by DSC and X-RPD data. Similar results were obtained by several authors when they used PVPs in preparation of solid dispersions of different drugs and confirmed the formation of amorphous phases of these drugs ${ }^{35-39}$. The increase in the dissolution observed for the physical mixtures may be due to the wetting properties of the carriers to the hydrophobic surface of the drug particles. 


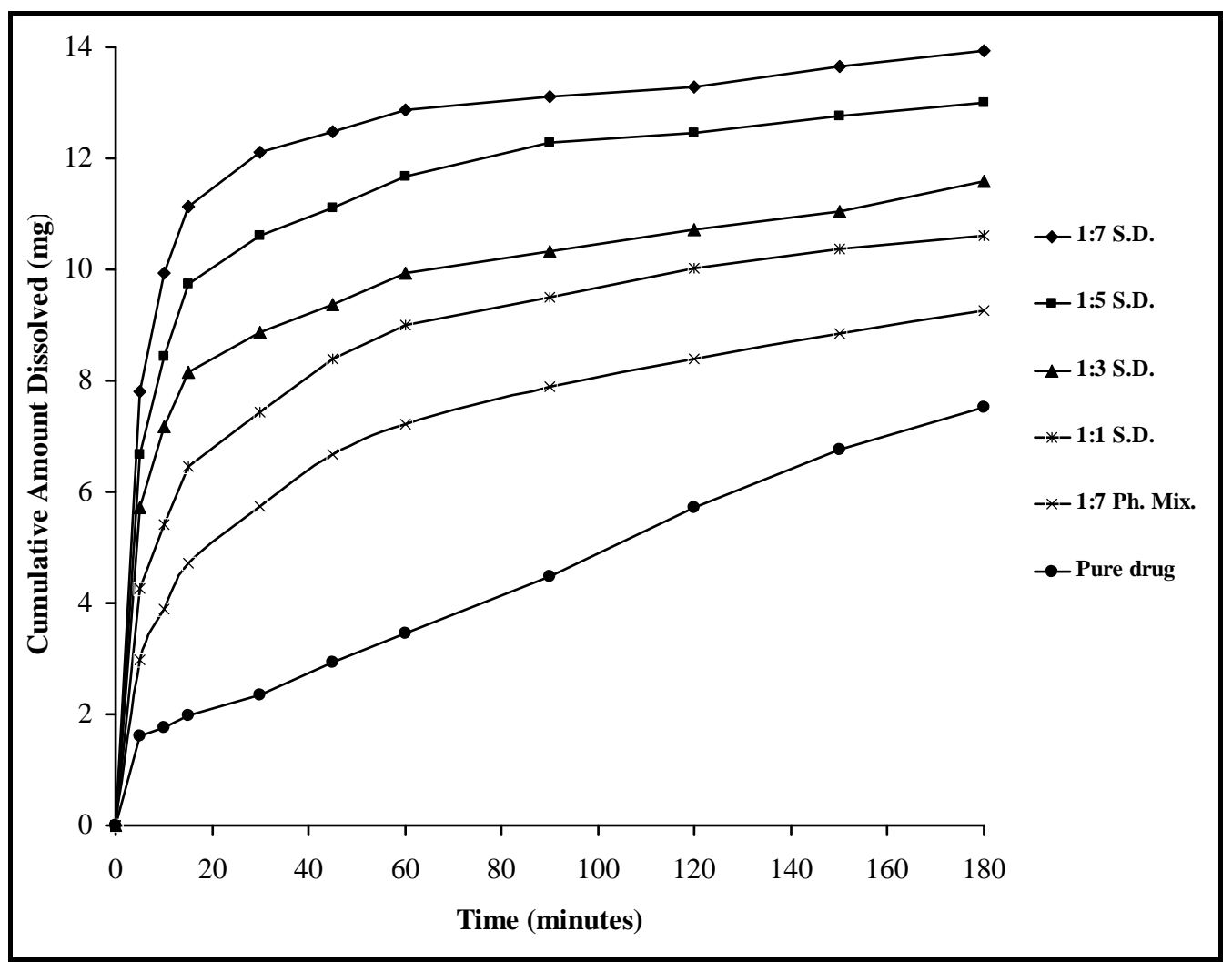

Fig. 6: Dissolution profiles of nimesulide from its physical mixture (Ph. Mix.) and solid dispersions (S.D.) with PVP K25.

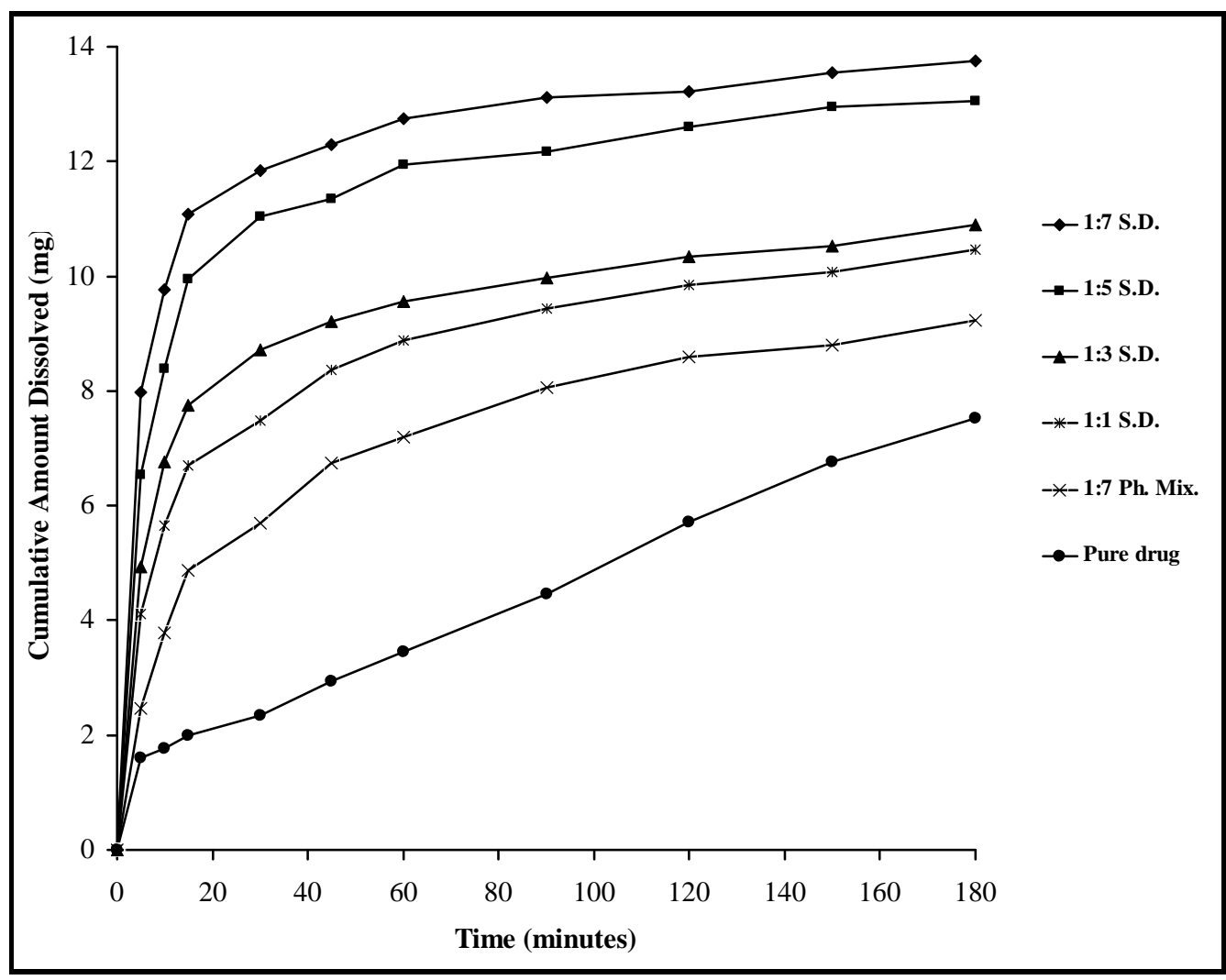

Fig. 7: Dissolution profiles of nimesulide from its physical mixture (Ph. Mix.) and solid dispersions (S.D.) with PVP 40000. 
The results of the dissolution studies of nimesulide/ $\beta-\mathrm{CD}$ and nimesulide/HP $\beta$-CD solid inclusion complexes and physical mixtures are graphically illustrated in Figure 8. It is observed that solid inclusion complexes of $\beta-\mathrm{CD}$ and HP $\beta-\mathrm{CD}$ exhibited higher dissolutions of 6.05 (3-fold) and 6.73 (3.4-fold) after 15 minutes, respectively compared with the pure drug (Table 3). This could be attributed to the improved solubility and/or reduction in crystallinity of nimesulide. The increase in the dissolution of nimesulide when it is physically mixed with CDs may be due to an improvement in the wettability and solubility of the drug in the aqueous CDs solutions resulting from the coexistence in the dissolution medium and the formation of inclusion complexes in solution ${ }^{40}$.

\section{Characterization of nimesulide solid dispersion with PVP 40000}

The dissolution rates of nimesulide were enhanced markedly when it was dispersed with PVPs. DSC, infrared spectroscopy, X-ray powder diffraction were conducted in order to examine the solid state characterization and the possible mechanism of the enhanced dissolution rate of the drug from its solid dispersion with PVP 40000.

\section{1- Differential scanning calorimetry (DSC) \\ The DSC thermograms of pure} nimesulide, PVP 40000, solid dispersion and corresponding physical mixture at weight ratio 1:7 are presented in Figure 9. Because of the amorphous structure of PVP 40000, no melting point peak was seen in the thermogram. The endothermic broad peak was attributed to the removal of water from PVP 40000. The DSC trace of the physical mixture shows the melting peak of nimesulide and the observed peak was reduced due to the low drug content. Solid dispersion did not show such peak, suggesting that nimesulide was molecularly dispersed in an amorphous form.

\section{2- X-Ray powder diffraction (X-RPD)}

The X-RPD patterns of pure nimesulide, PVP 40000, solid dispersion and physical mixture are shown in Figure 10. Nimesulide was found to exhibit a strong and characteristic $\mathrm{X}-\mathrm{RPD}$ pattern, showing the crystalline nature of the powder. PVP 40000 is an amorphous powder and characterized by the absence of any diffraction peaks. The X-RPD peaks of nimesulide physical mixture was detected but with reduced intensity, indicating that the crystallinity of nimesulide did not change. On the other hand, no peak was displayed from solid dispersion X-RPD pattern, indicating the presence of nimesulide in an amorphous form. Sekikawa et. $a l .{ }^{41}$ pointed out that PVP might inhibit the crystallization of drug and confirmed the DSC results.

\section{3- Infrared Spectroscopy (IR)}

Figure 11 depicts IR spectra of pure nimesulide, pure PVP 40000, nimesulide/PVP 40000 solid dispersion and the corresponding physical mixture at weight ratio of 1:7. Nimesulide (trace a) showed the $\mathrm{N}-\mathrm{H}$ stretching vibration at $3255 \mathrm{~cm}^{-1}$. This region of interest showed the evidence of interaction between nimesulide and PVP 40000 via intermolecular hydrogen bonding between the $\mathrm{N}-\mathrm{H}$ group of nimesulide with the $\mathrm{N}$ - or $\mathrm{C}=\mathrm{O}$ groups on pyrrolidone moiety.

On the other hand the IR spectrum of PVP 40000 displayed (trace b) broad peak at about $3440 \mathrm{~cm}^{-1}$ due to the presence of moisture and at $1645 \mathrm{~cm}^{-1}$ due to the $\mathrm{C}=\mathrm{O}$ stretching. The IR spectrum of the physical mixture still showed peak of N-H stretching vibration of nimesulide and seemed to be only the summation of both components which reflected that there was no interaction occurred. In solid dispersion the $\mathrm{N}$ $\mathrm{H}$ stretching vibration of nimesulide was not detected and a single absorption band at 3430 $\mathrm{cm}^{-1}$ and at $1641 \mathrm{~cm}^{-1}$ was observed. These peaks were shifted toward lower wave number, indicating the presence of intermolecular hydrogen bond between nimesulide and PVP 40000. Therefore, the amorphousness of nimesulide within the PVP 40000 might be predicted by the disappearance of the $\mathrm{N}-\mathrm{H}$ peak of nimesulide. This IR pattern was previously observed by Tantishaiyakul et. al. ${ }^{38}$ who demonstrated the presence of intermolecular hydrogen bonding between piroxicam and PVP in solid dispersion. Therefore, piroxicam presence in amorphous state was confirmed by the disappearance of $\mathrm{N}-\mathrm{H}$ or $\mathrm{O}-\mathrm{H}$ peak of piroxicam. 


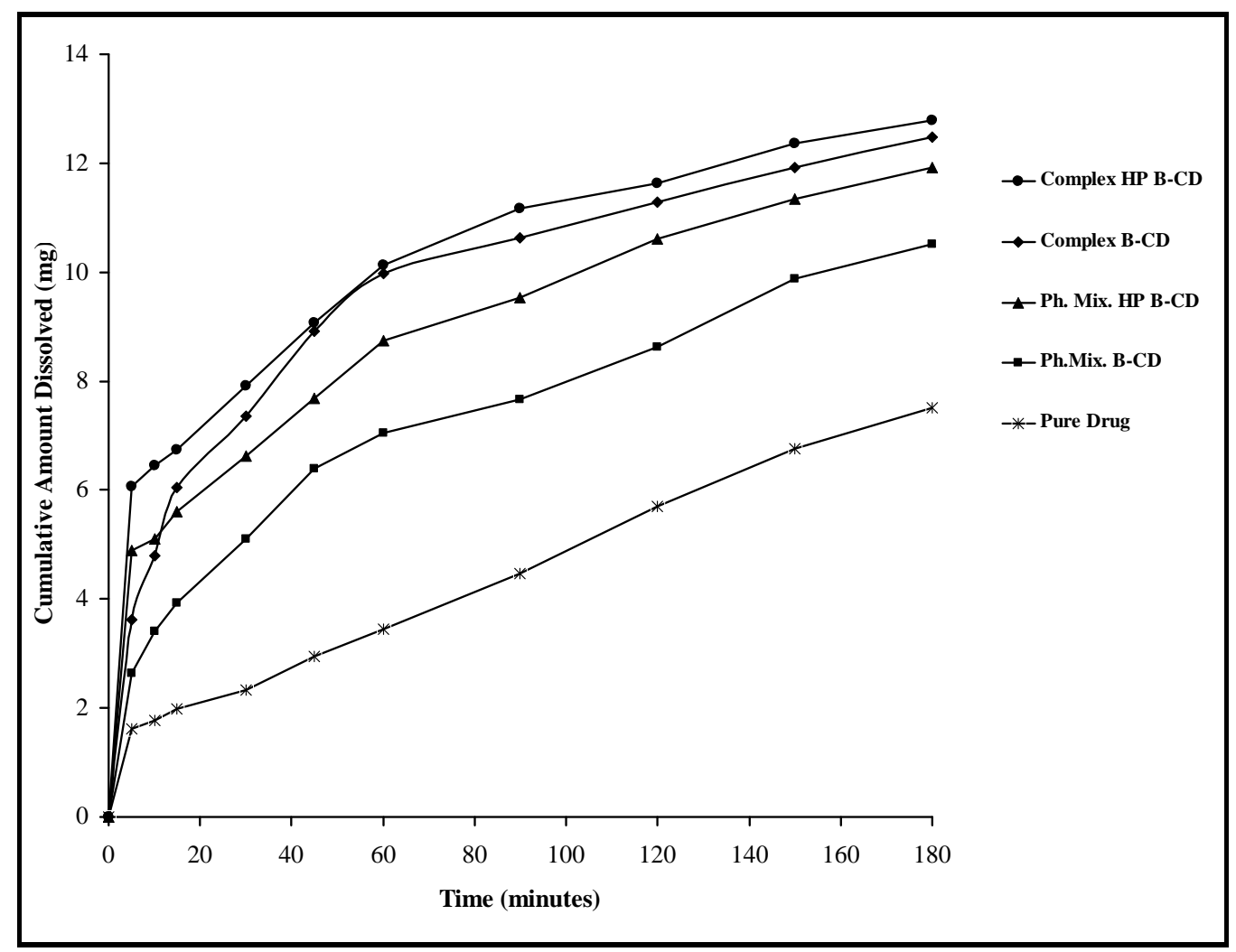

Fig. 8: Dissolution of nimesulide from its physical mixtures ( $\mathrm{Ph}$. Mix.) and inclusion complexes with $\beta$-CD and HP $\beta$-CD.

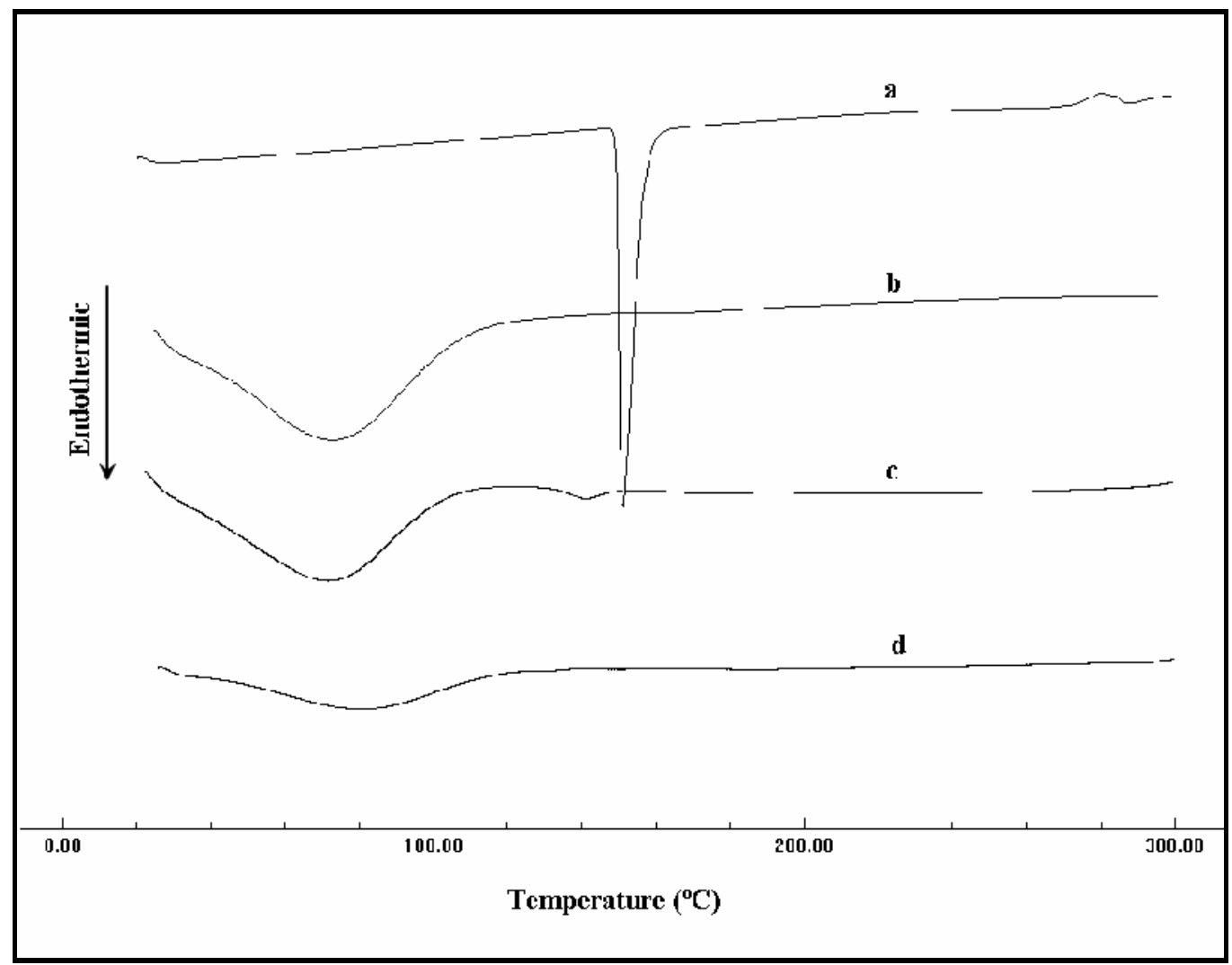

Fig. 9: DSC thermograms of (a): nimesulide (b): PVP 40000, (c): 1:7 nimesulide/PVP 40000 physical mixture and (d): 1:7 nimesulide/PVP 40000 solid dispersion. 


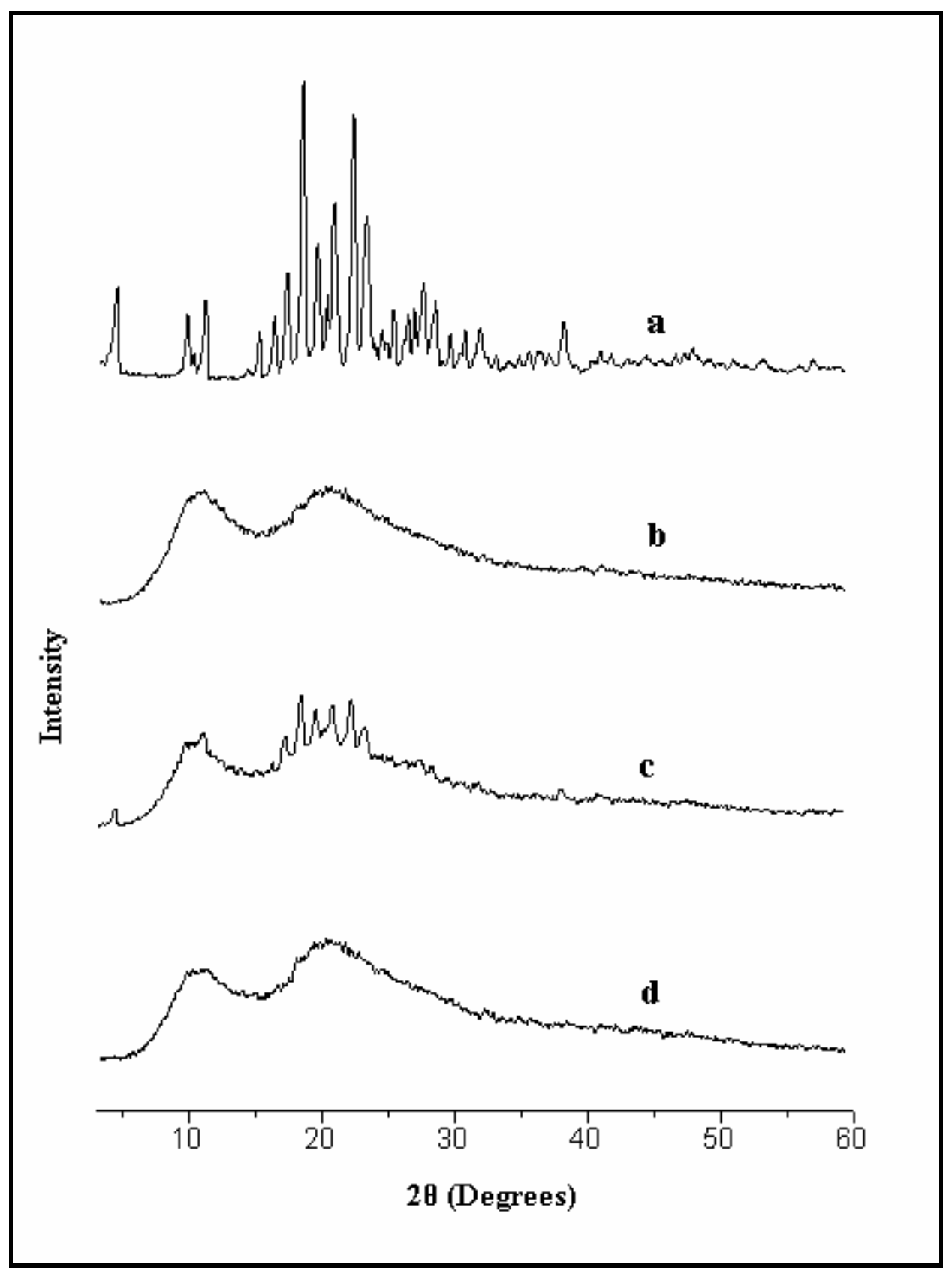

Fig. 10: X-Ray powder diffraction patterns of (a): nimesulide, (b): PVP 40000, (c): 1:7 Nimesulide/PVP 40000 physical mixture and (d): 1:7 nimesulide/PVP 40000 solid dispersion. 


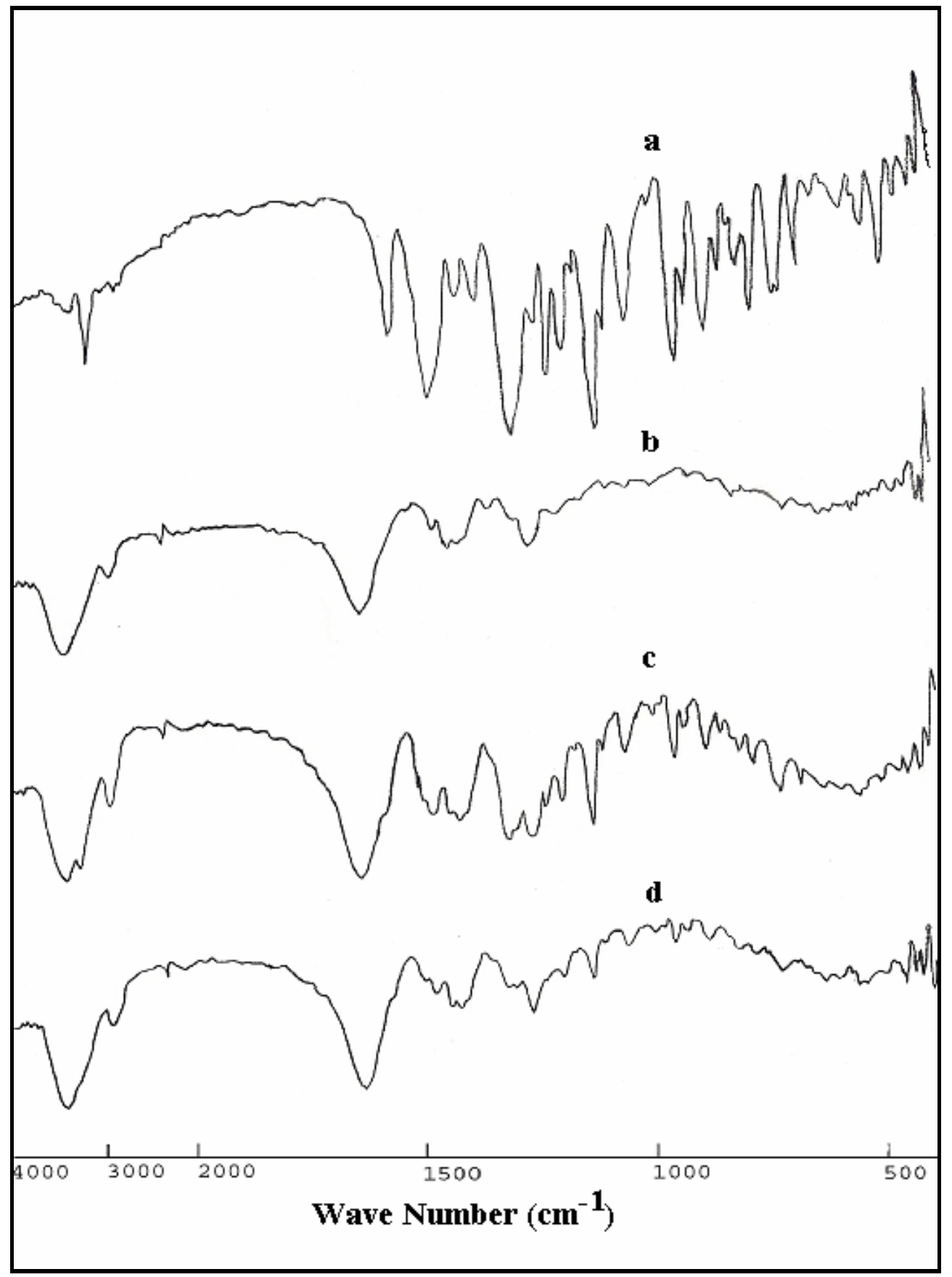

Fig. 11: IR spectra of (a): nimesulide, (b): PVP 40000, (c): 1:7 nimesulide/PVP 40000 physical mixture and (d): 1:7 nimesulide/PVP 40000 solid dispersion.

\section{4- Scanning electron microscope (SEM)}

Scanning electron microscope (Fig. 12) showed that nimesulide particles are in the form of tabular shaped crystals with smooth surfaces, while PVP 40000 appeared as large spherical particles of smooth surfaces. The SEM image of the physical mixture showed the individual nimesulide and PVP 40000 particles. The adherence of small crystal particles of nimesulide onto the surface of the lager particles of PVP 40000 indicating no interaction takes place between them. The solid dispersion revealed absence of crystalline structure of the drug. It is difficult to differentiate between particles of both components, indicating that there was an interaction between them. 


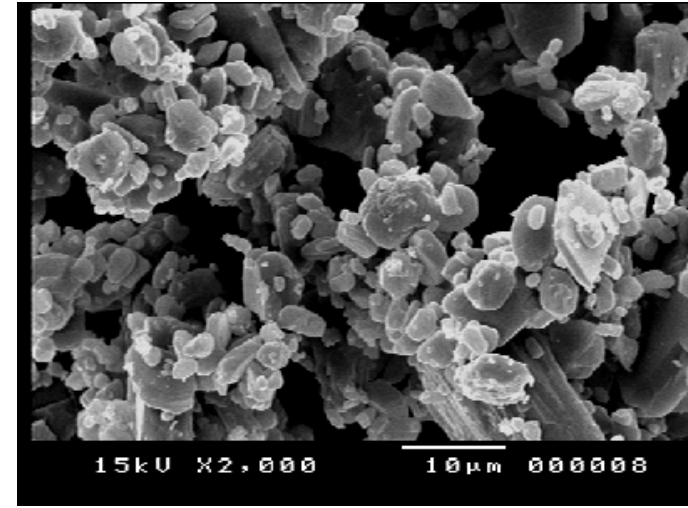

$\mathbf{a}$

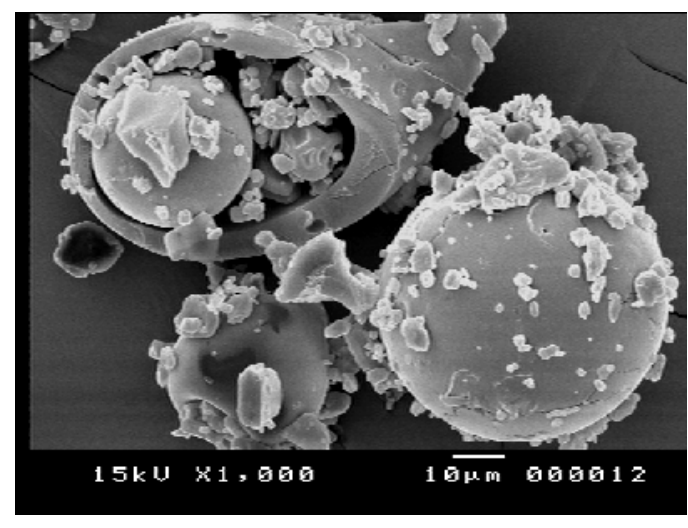

C

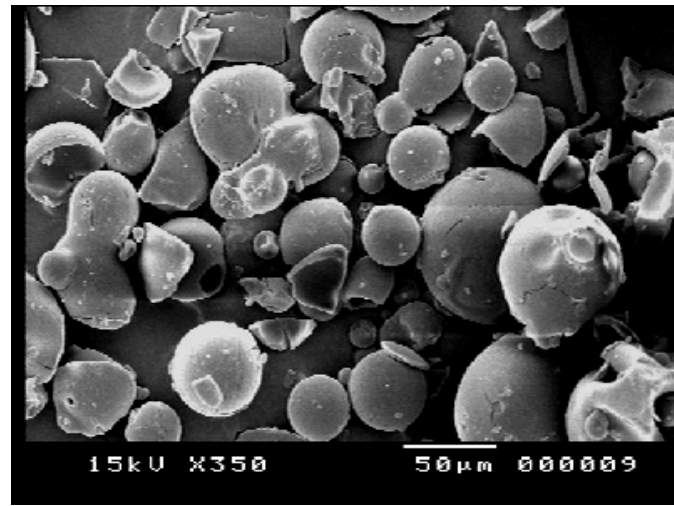

b

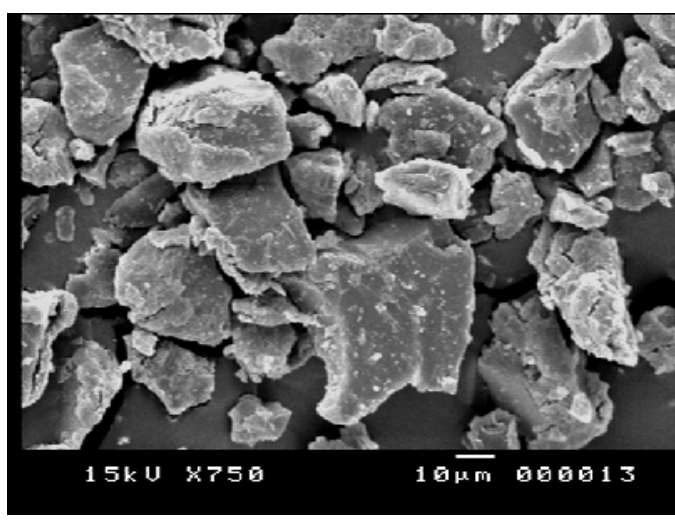

d

Fig. 12: Scanning electron micrographic of (a): nimesulide, (b): PVP 40000, (c): 1:7 nimesulide/PVP 40000 physical mixture and (d): 1:7 nimesulide/PVP 40000 solid dispersion.

\section{Conclusion}

Form this study, it could be concluded that DMA and brij 58 showed the highest solubilizing power among the investigated solubilizers. Eutectic mixtures were obtained by solid dispersion of nimesulide with PEGs and pluronics at a weight ratio of 1:9. The dissolution of nimesulide from its solid dispersions and inclusion complexes with the investigated hydrophilic polymers as well as cyclodextrins was clearly improved. PVPs exhibited the highest dissolution at weight ratio of 1:7. The presence of nimesulide in an amorphous form in its solid dispersion with PVP 40000 might be responsible for the enhancement in the dissolution as confirmed by DSC, X-RDP, IR and SEM. These systems will be further investigated in the release of nimesulide from different topical formulations.

\section{REFERENCES}

1- M. Vogt, K. Kunath and J. B. Dressman, "Dissolution Enhancement of Fenofibrate by Micronization, Cogrinding and SprayDrying: Comparison with Commercial Preparations", Eur. J. Pharm. Biopharm., 68, 283 (2008).

2- Q. Huang, J. Wang, G. Chen and Z. Shen, "Micronization of Gemfibrozil by Reactive Precipitation Process", Int. J. Pharm., 360, 58 (2008).

3- S. Tayel, J. I. Soliman and L. D. Nassif, "Carbamazepine Spherical Agglomerate Crystal. Part I: Preparation and Evaluation", Egypt. J. Pharm. Sci., 44, 101 (2003).

4- A. H. Al-Marzouqi, A. Solieman, I. Shehadi and A. Adem, "Influence of the Preparation Method on the Physicochemical Properties of Econazole- $\beta$ - 
Cyclodextrin Complexes", Eur. J. Pharm. Biopharm., 60, 85 (2008).

5- M. Sugimoto, T. Okagaki, S. Narisawa, Y.Koida and K. Nakajima, "Improvement of Dissolution Characteristics and Bioavailability of Poorly Water-Soluble Drug by Novel Cogriding Method Using Water-Soluble Polymer", Int. J. Pharm., 160, 11 (1998).

6- P. R. Nepal, H. Han and H. Choi, "Enhancement of Solubility and Dissolution of Coenzyme $Q_{10}$ Using Solid Dispersion Formulation", ibid., 383, 147 (2010).

7- S. H. Yalkowsky and T. J. Roseman, "Solubilization of Drugs by Cosolvents", In: Techniques of Solubilization of Drugs, S. H. Yalkowsky, 12, Marcel Dekker Inc., USA, 1981, pp. 91-134.

8- K. Kawakami, N. Oda, K. Miyoshi, T. Funaki and Y. Ida, "Solubilization Behavior of a Poorly Soluble Drug Under Combined Use of Surfactants and Cosolvents", Eur. J. Pharm. Sci., 28, 7 (2006).

9- P. Jain and S. H. Yalkowsky, "Solubilization of Poorly Soluble Compounds Using 2-Pyrrolidone", Int. J. Pharm., 342, 1 (2007).

10- R. Patel, G. Buckton and S. Gaisford, "The Use of Isothermal Titration Calorimetry to Assess the Solubility Enhancement of Simvastatin by a Range of Surfactants", Thermo. Acta, 456, 106 (2007).

11- H. O. Ammar and S. A. Nahhas, "Solubilization of Bromhexine Hydrochloride by Non-Ionic Surfactants", Pharmazie, 49, 583 (1994).

12- C. Leuner and J. Dressman, "Improving Drug Solubility for Oral Delivery Using Solid Dispersions", Eur. J. Pharm. Biopharm., 50, 47 (2000).

13- Y. Ozkan, N. Doganay, N. Dikmen and A. Isimer, "Enhanced Release of Solid Dispersions of Etodolac in Polyethylene Glycol", IL Farmaco, 55, 433 (2000).

14- A. M. Abdul-Fattah and H. N. Bhargava, "Preparation and In-vitro Evaluation of Solid Dispersions of Halofantrine", Int. J. Pharm., 235, 17 (2002).

15- E. Kim, M. Chun, J. Jang, I. Lee, K. Lee and H. Choi, "Preparation of a Solid
Dispersion of Felodipine Using a Solvent Wetting Method", Eur. J. Pharm. Biopharm., 64, 200 (2006).

16- R. Challa, A. Ahuja, J. Ali and R. K. Khar, "Cycldextrins in Drug Delivery: An Updated Review", AAPS PharmSciTech, 6, E329 (2005).

17- S. K. Kulkarni, "On the Safety of Nimesulide, a Preferential COX-2 Inhibitor", Curr. Sci., 83, 1442 (2002).

18- A. Singh, P. Singh and V. K. Kapoor, "Nimesulide, In: Analytical Profile of Drugs Substances and Excipients", 28, Academic Press, India, 2001, pp. 197-249.

19- B. N. Nalluri, K. P. R. Chowdary, K. V. R. Murthy, A. R. Hayman and G. Becket, "Physicochemical Characterization and Dissolution Properties of Nimesulide Cyclodextrin Binary Systems", AAPS PharmSciTech, 4, 1 (2003).

20- B. N. Nalluri, K. P. R. Chowdary, K. V. R. Murthy, V. Satyanarayana, A. R. Hayman and G. Becket, "Inclusion Complexation and Dissolution Properties of Nimesulide and Meloxicam-Hydroxypropyl- $\beta$-Cyclodextrin Binary Systems", J. Incl. Phenom. Macrocy. Chem., 53, 103 (2005).

21- L. Zhao, P. Li and S. H. Yalkowsky, "Solubilization of Fluasterone", J. Pharm. Sci., 88, 967 (1999).

22- Y. He, P. Li and S. H. Yalkowsky, "Solubilization of Fluasterone in Cosolvent/Cyclodextrin Combinations", Int. J. Pharm., 264, 25 (2003).

23- N. Seedher and S. Bhatia, "Solubility Enhancement of COX-2 Inhibitors Using Various Solvent Systems", AAPS PharmSciTech, 4, 1 (2003).

24- M. W. Samaha and M. A. F. Gadalla, "Solubilization of Carbamazepin by Different Classes of Nonionic Surfactants and a Bile Salt", Drug. Dev. Ind. Pharm., 13, 93 (1987).

25- A. A. Ismail and M. A. F. Gadalla, "Effect of Selected Surfactants on Nalidixic Acid Solubility", Pharmazie, 38, 733 (1983).

26- A. H. Ghanem, H. El-Sabbagh and H. Abdel-Alim, "Solubilization of Flufenamic Acid", Pharm. Ind., 42, 854 (1980).

27- A. E. Aboutaleb, A. A. Ali and R. B. Salama, "Micellar Solubilization of 
Quinethazone, Levomepromazine and Niridazole", Pharmazie, 36, 35 (1981).

28- M. Guyot, F. Fawz, j. Bildet, F. Bonini and A. M. Lagueny, "Physicochemical Characterization and Dissolution of Norfloxacin/Cyclodextrin Inclusion Compound and PEG Solid Dispersions", Int. J. Pharm., 123, 53 (1995).

29- D. Bikiaris, G. Z. Papageorgiou, A. Stergiou, E. Pavlidou, E. Karavas, F. Kanaze and M. Georgarakis, "Physicochemical Studies on Solid Dispersions of Poorly Water-Soluble Drugs Evaluation of Capabilities and Limitations of Thermal Analysis Techniques", Thermochem. Acta, 439, 58 (2005).

30- G. M. Khan and Z. Jiabi, "Preparation, Characterization and Dissolution Studies of Ibuprofen Solid Dispersions using Polyethylene Glycol (PEG), Talc and PEG-talc as Dispersion Carriers", Drug Dev. Ind. Pharm., 24, 455 (1998).

31- A. V. Kobanov, E. V. Batrakova and V. Y. Alakhov, "Pluoronic ${ }^{\circledR}$ Block Copolymers as Novel Polymer Therapeutics for Drug and Gene Delivery", J. Control. Rel., 82, 189 (2002).

32- M. Newa, K. H. Bhandari, D. X. Li, T. Kwon, J. Kim, B. K. Yoo, J. S. Woo, W. S. Lyoo, C. S. Yong and H. G. Choi, "Preparation, Characterization and In-vivo Evaluation of Ibuprofen Binary Solid Dispersions with Poloxamer 188", Int. J. Pharm., 343, 228 (2007).

33- Y. Chen, G. G. Z. Zhang, J. Neilly, K. Marsh, D. Mawhinney and Y. D. Sanzgiri, "Enhancing the Bioavailability of ABT963 Using Solid Dispersion Containing Pluronic F-68, ibid., 286, 69 (2004).
34- S. Chutimaworapan, G. C. Ritthidej, E. Yonemochi, T. Oguchi and K. Yamamoto, "Effect of Water Soluble Carriers on Dissolution Characteristics of Nifedipine Solid Dispersions", Drug Dev. Ind. Pharm., 26, 1141 (2000).

35- A. Paradkar, A. A. Ambike, B. K. Jadhav and K. R. Mahadik, "Characterization of Curcumin-PVP Solid Dispersion Obtained by Spray Drying", Int. J. Pharm., 271, 281 (2004).

36- H. Konno, T. Handa, D. E. Alonzo and L. S. Taylor, "Effect of Polymer Type on the Dissolution Profile of Amorphous Solid Dispersions Containing Felodipine", Eur. J. Pharm. Biopharm., 70, 493 (2008).

37- V. Tantishaiyakul, N. Kaewnopparat and S. Ingkatawornwong, "Properties of Solid Dispersions of Piroxicam in Polyvinylpyrrolidone K-30", Int. J. Pharm., 143, 59 (1996).

38- V. Tantishaiyakul, N. Kaewnopparat and S. Ingkatawornwong, "Properties of Solid Dispersions of Piroxicam in Polyvinylpyrrolidone", ibid., 181, 143 (1999).

39- E. Broman, C. Khoo and L. S. Taylor, "A Comparison of Alternative Polymer Excipients and Processing Methods for Making Solid Dispersions of a Poorly Water Soluble Drug", ibid., 222, 139 (2001).

40- K. Rajendrakumar, S. Madhusudan and T. Pralhad, Cyclodextrin Complexes of Valdicoxib: Properties and AntiInflammatory Activity in Rat", Eur. J. Pharm. Biopharm., 60, 39 (2005).

41- H. Sekikawa, M. Nakano and T. Arita, "Inhibitory Effect of Polyvinylpyrrolidone on the Crystallization of Drugs", Chem. Pharm. Bull., 26, 118 (1978). 